TIE TOPOGRAPHIC DIAGNOSIS OF SUB'TENTORIAI, BRAIN 'TUMORS *

HERMAN H. HOPPE, A.M., M.D.

Professor of Netrology, Medleal Department Unlversity of Cinclnwat1; Neulologist to Cincinmatl Ilospitul

CINCINNATI

\section{TOPOGRAPIIL DIAGNOSIS}

'The question as to whether or not we shall operate for' tumors in this region, and if we operate, whether the operation slall be radical or palliative, can be decided only by an accurate topographic diagnosis. The subject of differential topographic diagnosis is therefore of prime importance. Surgical intervention is dangerous, or not, in the cercbcllar region in direct ratio to the amount of exploration, handling and bruising to which the cerebellum is subjected. Moreover, if we know, from the location of the growth, that the chief disturbance prodiced is by an internal hydrocephalus, as in Case 1 , the nature of the surgical interference will be

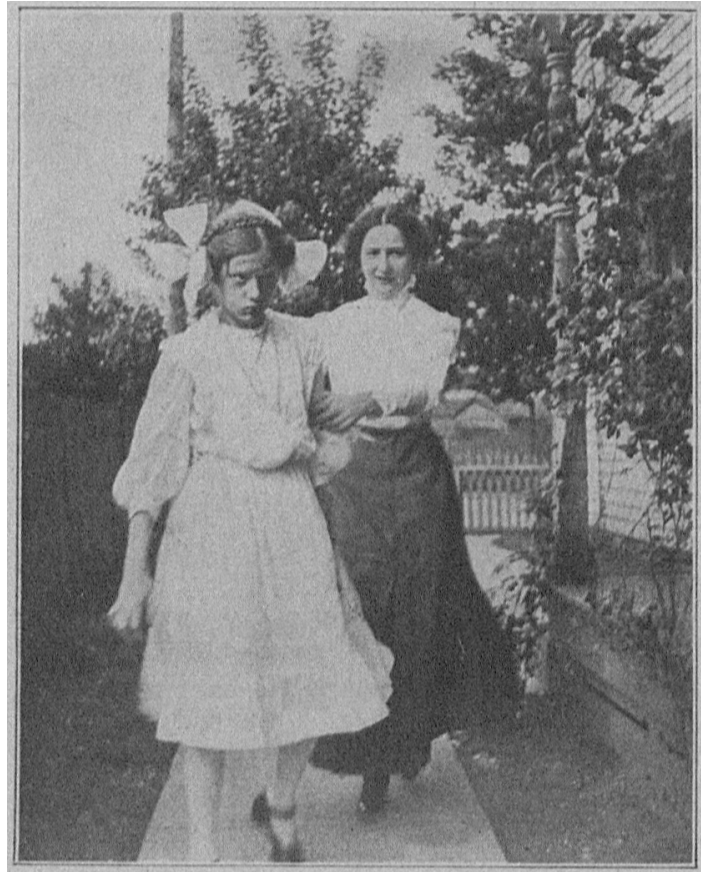

Fig. 1, Case 2.--The photograph fllustintes paralysls of light

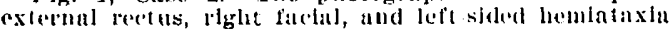

different from that which is indicated if the growtl itself. by local pressure, is threatening the life of the patient. More accurate topographic diagnosis will not only enable us to be more precise in adrocating or retusincr to adrise surgical intervention, but it will cnable us to say whether the sulfoceipital or subtemporal yegion is to be the scat ol the operation, and, if stuoccipital, which side.

Have we signs sulficienty positive to enable us to say that a grosth is in the braninstem, in the corebellopontine angle or intracesebellar, and il the latter, on Which side it is localecl?

'The cerolural surgionl trimmphs of the last decade have been adhowed in relieving cysts and tumors of the cercbellum itself, and those of the cerebello-pontine

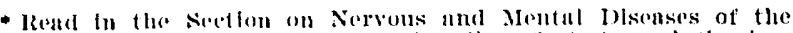

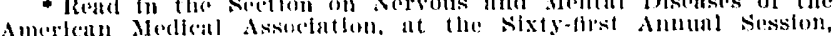

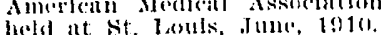

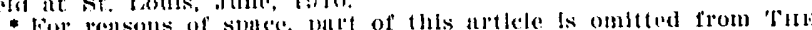

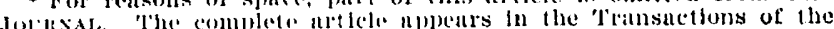
section and hil the athlior's leperints. angle. The diagnosis of the latter growth, as we shall see, is compraratively easy. $1 \mathrm{t}$ is the chief object of this paper to analyze the signs and symptoms which indicate a lesion of the cerebellum itself. I shall assume that such a loculization can be arrived at only by exclusion, and I shall therefore briefly state the history of cases, in which there were illustrative lesions, which must be excluded in the topographic diagnosis of intracerebellar growths.

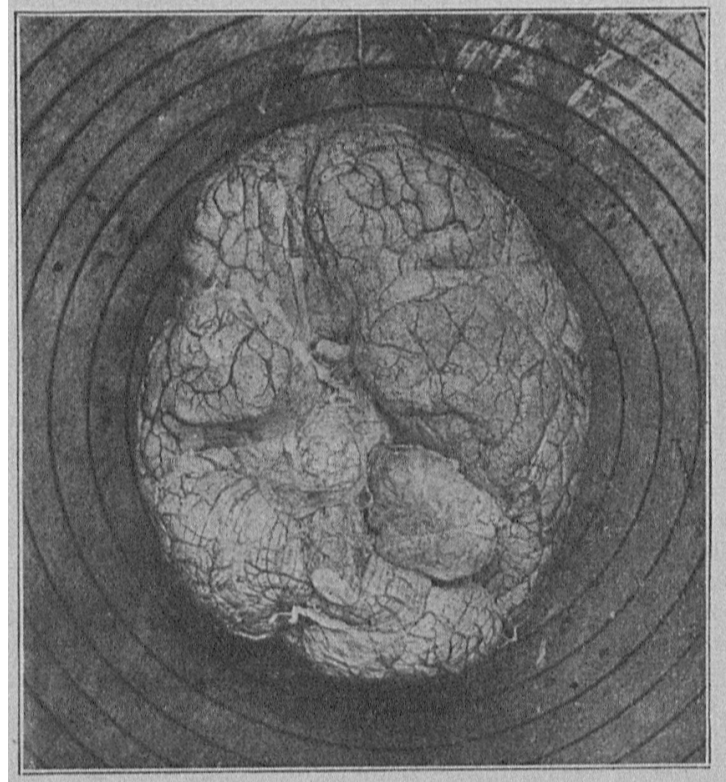

Fig. 2. Case 3.-Typient tumor of the left acoustic nerve in the left cerebello-pontine suble.

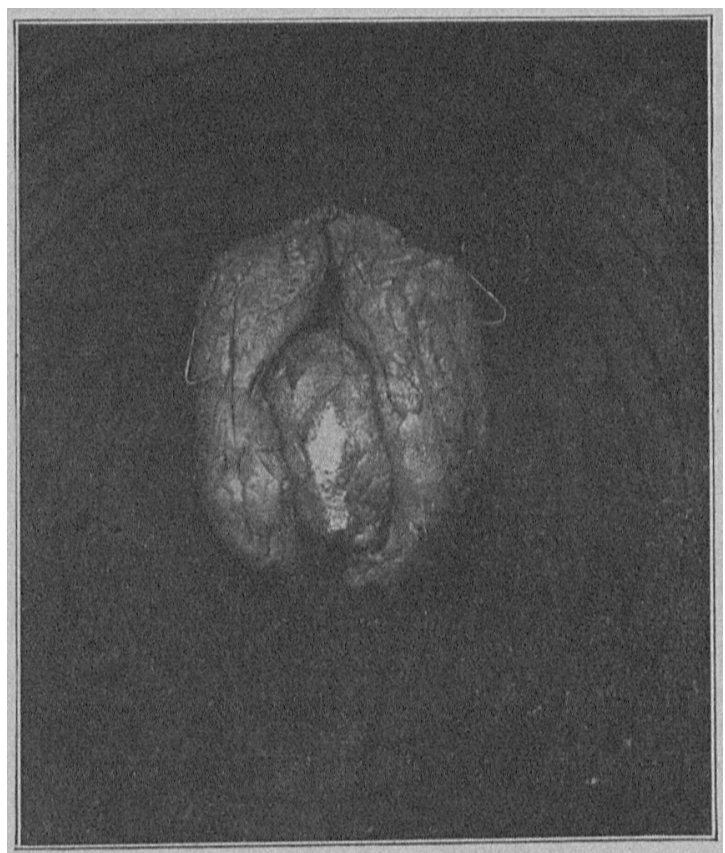

Fig. 3. Case 6.-Tumor of the right frontal lobe slmulating a ccrebellat syuptom-complex.

\section{TUMORS OF CORPORA QUADRIGEMINA}

'The first ease to which I shall call attention is typical of tumors of the region of the corpora quadrigemina. I shall give but a brief outline of the history, because the case itsell will form the hasis of a future paper.

We have here a typieal case which illustrates the syndrome of tumors of the corpora quadrigemina: Paralysis 
of the external eye-mmscles, involvement of both eyes, inability to turn eyeballs upward, ability to turn them down, pupillary paralysis, ptosis of both lids, blindness, incoordination of gait, some staggering static ataxia; no loss of sensation or of motor power in the extremities. The only discordant note is that deafness is often assor $i$. ated with lesion of the corpora quadrigemina, but in our case hearing remained normal. The other unusual leature is the extreme ataxia which came on toward the end. Patient when in bed used arms and legs freely but was unable to stand at all on account of the atrxia. and showel marked retropulsion on attempting to walk. Intention tremor, athetosis and nystagmus were absent in this case. The autopsy showed that the tumor was practically limited to the corpora-quadrigeminus region.

\section{TUAORS OF TONS}

Tumors of the pons offer quite a different syndrome from that of the tumors of the region of the corpora quadrigemina as the following case will jllustrate:

CASE 2.-Patient.-C. W., aged 12, school-girl. Family history was negative. 'There was no tuberculosis in the immeliate family. Patient was well up to four months ago. Onset of trouble was marked by a slight defeet in the right eye; patient saw double; at times lad some fever; headache oceasionally at first; later, more frequent, aud just previous to the time she was first seen had attacks of vertigo, and staggered; had vomited every morning. No defect of heuring.

Examination.-At the time of examination the mental condition was normal; pupils equal and responded to light; optic disks normal; there was paralysis of both internal and both external recti muscles; the eyes could be moved upward and downward; paralysis of the right facial, both upjer and lower branches; right eye could not be closed. The tongue deviated to left; arms were normal in all respects; in the right leg the patellar reflex was practically abolished; left patellar reflex exaggerated; left ankle-clomus, bilateral Babinski sign; no weakness in legs; hearing normal; when eyes were closed patient walked with a staggering gait, with a tendency to turn toward the left. There was no static ataxia, no ataxia in recumbent position.

Conrse of Discase.-Two weeks later the condition remained the same, but a horizontal nystagmius had been developed, on looking to right. After four weeks there developed an ataxia of both arms, without any loss of museular power; with blindfolded eyes patient could not walk forward at all, but invariably was forced towa'd the left. She staggered to left when walking, and fell to left in Romberg test. Hearing had become defective in the right ear, both to bone and air conduction. Papilla remained normal; left eye movement upward somewhat diminished; left patellar reflex had re. turned and both were now exaggerated.

May 24, 1910, mental condition was good; optic dises normal; eye muscles as before; paresis of soft palate; pationt choked on swallowing. light side of fnce remained unchanged; no loss of sensation anywhere; no areflexia cornen. Speech was difficult; dysarthria was present; patient developed someweakness, but a very acute ataxia of the left side, both arm and leg; adiadokokinesia of the left arm was marked; patient was unable to walk without assistance on account of the leftsided ataxia. Ankle-clonus was present on the left side; exaggerated patellar reflexes.

This case presented the typical history of an infiltrating tumor of the pons. The damage wrought is caused by a gradual destruction of the various nuclei and structures of the pons, partly by invasion, partly by compression.

The symptoms are chiefly bilateral; viz., bilateral involvement of the eyes, bilateral ataxia of the arms, bilateral increase of the patellar reflexes, but the involvement of the seventh and eighth on the riglit side, paresis of the left leg with ankle-clonus on the left side and ataxia of left arm and leg later on, shows the typical condition of pontine and inedullary growths, viz., paralysis alternans.

\section{TUMORS OF CEREBLLLO-PONTINE ANGLE}

And now let me call attention to tumors of the cerebello-pontine angle. 'The typical tumor liere is of very slow growth, uslaally a fibroma or endothejoma, growing from the trunk of the auditory nerve; but the seventh and fifth may also be the seat of origin. T'he typical early syndrome is that of defective hearing on one side, gradually increasing, with occasional attacks of vertigo, with loud noises and ringing in the car; then the general symptoms of headache, vomiting, vertigo, unsteady gait, plus more or less pronounced involvement of the fifth, sixth, seventh and eighth cranial nerves, on one side, with perhaps an indication of ataxia of arm or leg on the same side, and finally, signs and symptons which point to a compression of the medulla and pons. This syndrome is so typical that in the majority of cases the localizing diagnosis is easy. let me here introduce a typical case:

Cise 3.-Patient.-R. M. R, aged 49, examined July 9 1908. Father of four children; superintendent of Normal scliool, state of Kentucky; patient of 0 . J. Smith, Lexington, Ky. He had lad meningitis (?) when 9 years old; no venereal discases; influenza yearly for five or six years; had been partially deaf in the left ear for the previous six years. Dr. Smitl wrote that in March, 1907, patient had "some contl'uetion of the field of vision, occasional sinistral hemianopia, dextral arm and leg numbness, and inability to nominate with his usual facility." Patient stated that for the previous year he had had occasional attacks of vertigo and could not see out of the temporal half of the left eye; that he could not hear well with his left ear. He staggered at times, but to no special side; lost confidence when he attempted walking in the dark.

Fxanination.-Mental condition, memory and speceh normal; left pupil somewhat larger than the right; both responded to light and accommodation; no choked disk; some weakness of internal rectus of right eye and external rectus of left; horizontal oscillations of eyeballs when turned to axtreme left, but no typical nystagmus. The patient could not hear well in left ear, but bone conduction was normal. Sen. sation in the facial region was normal; reflexes of cornea normal. No loss of function in regions supplied by the other eranial nerves. Sensution, muscular power and reflexes of the extremities normal; no atuxia in upper or lower extremitics.

Diagnosis.-No positive diagnosis could be made; neoplasin suspected.

During his vacation patient noticed that his gait was slightly atuxic. In October and November, 1008, he suddenly fell on two occasions. His legs simply gave way under him; was able to arise unassisted and go on with his work.

Feb. 10, 1909, patient stated that he liad some headnche and vertigo in the fall of 1908 ; that he was unstendy on his feet and staggered occasionally as if drunk. Six weeks prior to above date he had a sudden onset of violent headaches and vomiting. This continued since; pationt was confined to bed and treated for uremia.

Examination.-Patient laad not been uble to walk without support, and when put on his feet staggered and fell to the left. He was very weak; pulse 90 ; vomited constantly, and had violent headuches. Pupils reacted to light. Patient had very marked choker disks, but could see well; stated that vision in left eye became blurred occusionally; weakness of internal rectus of right eye and external reetus of left eyt; horizontal wavering of eyeballs when turned to the left. (Nystagmus?). He sliowed a tendency to lie on left side; gait weak and staggering, and fell to the right; no typical cerebellar gait. Nasolabial fold seemed less marked on right side than on the left. No ataxia of the arm; right arm normal in muscular power; the right leg was perhaps a little weaker than the left; urinalysis negative. 
Course of Disease-For two weeks patient stopped vomiting; then vomited oceasiomaly. Seemed much improved o.l trentment of jodid of potassiutn. No new symptoms or signs developed for six weeks.

April 5, 1909: Rapid increase, rather suddenly, of weakness in the legs; when put on feet, fell to the right and dragged the right leg. Reflexes of legs exnggeratid; had suddenly developed bilateral ankle.clonus and slight patellar clonus; plantar reflex nornul on both sides; no disturbanes of sensa. iion, no ntaxia in the recumbent position, no wealsuess of arms; other signs and symptoms remuined as before, except pulse, which was very weak; 120 per minute.

Diagnosis. - Cerebellar tumor, probubly on the left side. Dr. Ransohofi was enlled in to operate. Dr. Zenner also suw the case.

Operafion.-On account of the wealiness of the patient, it was decided to do a typical subtemporal decompression on the right side, rather than take the increased risk of perhaps a lifnteral subocepital operation. The bulging of the dura was cnormous; dura opened and pulsation in brain reestablished; pationt left opernting room barely alive, on account of cardiac weakness. Twenty-four hours after operution pntient suddenly developed a typieal tachycardin; pulse 240 beats per minute at heart: irregular, no rndial pulse. This condition yjelded to stimulation and subcutaneons infusions of salt solution, pulso returning to 108 . The bilateral nnkleclomus disappeared, leadache and vomiting censed, and patient became comfortable.

subsequent Coursc- - On thiod day paralysis of the pharyox wis noticed, und up to his dentl patient was unable to swal. low. On the fifth day patient had a convulsion, suddenly lost conscionsuess, became rigid all over, head thrown back in opisthutomus, radial pulse lost, tachycardia again persistent, respi. ration suspended; marked asphyxin. Putient recovered consciousness and seemed fairly well with the exception of the puralysis of the pharyux. In twenty-four hours he had a second attack of convulsions; this was followed by tachyeardia and quick, shallow respiration. There was a ptosis of the right eyelid, loss of corneul refiex, cornenl ulceration on the left rye; no loss of sensution in the left side of fuce. There was paralysis of the right arm and right leg, and perhaps of the left leg; denth.

Autopsy.-This was made three hours after death. The cerebrum was dry and appurently completely drained of cerebrospinal fluid. There was more fluid below the tentorim calebelli. On removing the tentorium, a tumor, the size of an English walmut, was found partly attaclied to the petrous portion of the temporal bone, loosely adlierent, but apparently growing from the left acoustic nerve. It secmed so soft ns to give the impression of being a cyst. The fifth nerve was stretehed over the midlle of the tumor, anteriorly. The entirs corebellum and brain stem secmed displaced, more especially the left lobe of the ecrebellum, which was displaced downwurd and bnckward. The lower left half of the pons and adjacent portion of the medulla were markelly compressed (Fig. 2).

The case also illustrates the difficulties in localizing even such a typical tumor as neoplasms of the acoustic nerve in the cerebello-pontine angle. Theoretically, this should be easy, but Bruns, cushing and others have called attention to the absence of signs, and in this case up to within a few days of the operation there were practically no symptoms and signs which indicated with any degree of certainty that the growth was in the cerebello-pontine angle. I believe in our case the extreme softness, almost fluid consistency of the growth during life (although it became quite solid in formaldehyd solution), accounts for the absence of symptoms of pressure; the nerve trunks, being more firm than the tumor itself, were not compressed. Even the filth nerve, which was stretehed anil flattened out over the tumol, showed no signs of loss of function, exerpt. twenty-four hours before death.

In this case we have typical history of a gradual diminution of hearing in !eft ear (side of lesion) beginning six years before the tumor cuused general symptoms.
Horizontal oscillations (jerking) of the eyeballs when turned toward side of lesion. No areflexia cornea at any period before the operation except a few days before death, althongh the autopsy showed that the fifth nerve was flattened into a ribbon over the tumor. 'There was no clange in sensation, muscular power and reflexes in either upper or lower extremities. There was no choked disk until two montls before the operation. In a word for six years after begimning deafness was noticed, no signs or symptoms of tumor of the cerebello-pontine angle were present. A few months before the operation, however, all general and focal signs rapidly set in. Then we have attacks, not continuous, of staggering grait; two attacks of astasia-abasia; inability to walk on account of static ataxia. Patient falls to the left; has no objective loss of power in arms or legs; perhaps a slight wenkness of right leg; no atnxia of either arm; nystagmic jerking; weakness of internal rectus of right cye and external rectus of the left. Gait is not typically rerebellar; later on, weakness of right leg develops; bilateral ankle clomus; no ataxia in either upper or lower extremities when in recumbent position; no disturbance of sensation.

\section{BASILAR MENINGITIS SIMULATING TUMOR}

In this connection it is appropriate to note another case* which I believe to be a case of basilar syphilitic meningitis, although there is no antopsy report to confirm the diagnosis. Both Weisenberg and Mills have placed similar cases on record. Oppenheim in a recent case report warns us not to place too much importance on a positive Wassermann reaction or on temporary sucess of the antisyphilitic treatment, in a similar case.

'This case was one of a typical sindrone of tumol' of the cerebello-pontine angle: (General symptoms of brain tumer plus one-sided involvement of the fifth, sixth, seventh and eighth nerves, with ataxia of one extremity on the same side.

The facts, however, that the pationt had had a paraplegia six years before which disappeared completely uniler potassium iodid, and that she died suddenly with all the signs of an acute bulbar palsy, led me to believe that the case was one of basilar sypliilitic meningitis. I did not recommend an operation. but placed hier on gray oil injections, ton late, however, to accomplish any results. This case only strengthens the rule that a careful history and a consideration of the symptoms in the chronologic order of their oecurrence is neeessary to make the differential diagnosis.

\section{EARLY DIAGNOSIS}

I cannot lay too much stress on the early diagnosis of tumors of the cerebello-pontine angle. They are very amenable to surgical treatment, as the numerous cases on record testify; but when the case has advanced to the point of compression of the pons, as in my case, little is to be hoped for from surgical interference. The aurist should be the first to recognize these cases, because of the early involvement of hearing, and should be on the lookout for the early symptoms, viz,, progressive loss of hearing with midnle ear normal, vestibular attacks of veltigo, slight weakness of face and areflexin cornea on the same side, with perhaps weakness of external rectus of same eye. No other focal lesion, with the possible exception of basilar syphilis, produces this sindrome.

* The details of the history are given in the Transactions and in the author's reprints. 
After the consideration of these cases we may say that tumors of the cerebello-pontine angle show a predominance of unilateral focal signs on part of the fifth, sixth, seventh and eighth, whereas tumor's of the pons and melulla show bilateral focal signs with a clear indication of hemiplegia alternate. In both, the focal signs may precede the general signs of brain tumor, and frequently do. Pons and melulla tumors, being small, produce less marked general signs of brain tumor, whereas, the angle tumors have later on marked general signs. Choked disk is characterized by its absence in pons tumors, although this is not invariably the rule, whereas, the cerebello-pontine angle tumors manifest general signs. Choked disk is almost invariably present, together with headache, vomiting and vertigo, partly due to an associated internal hydrocephalus.

\section{DIAGNOSIS OF CYSTS AND TUMOIRS OF CEREBELLUM}

And now let us proceed to the consideration of that part of our subject which to my mind has the greatest practical importance, namely, the early diagnosis of cysts and tumors of the cerebellum itself. When these tumors and cysts have grown to such a size as to compress the cranial nerves and the pons itself, the diagnosis is not difficult, but the surgical prognosis is bad; whereas, the outlook is good if an early localizing diagnosis can be made before the tumor has grown beyond the confines of the cerebellum. This early diagnosis is very difficult. Not only is it difficult to say whether the growth is located on one side or the other, in the hemisphere, but it is often difficult to rule out the growths of the frontal lobe or to say with certainty whether the symptom complex is caused by a tumor, by acquired internal hydrocephalus, or whether we are dealing with the so-called pseudo-tumor symptom-complex.

\section{CEREBELLAR CASES}

Let me briefly introduce two cases here which will illustrate the difficulty of making an early exact localizing diagnosis in cerebellar cases:

Case 5.-I'atient.-J. P. C., Nashville, Tenn., a man aged 47, single; occupation, shect-writer. Parents both dead; cause unknown. The patient lad never had syphilis or a chancre; lıad been a drinking man for past ten years, but had never been sick. Onset of present illness eight months previous to examination. The chief symptom was a constant headache, usually oceipital, but at times frontal. 'l'hese headaches were very severe in claracter, and the periods of freedom were few and short in duration. Any physical strain, and also cough. ing, made the headache worse. When the hendaches were bad the patient was confined to bed, but when he attempted to walk he staggered and showed a tendency to fall to the right.

Exaninution.--May 30, 1009. The pupils were equal in size, and responded to light. 'The eyeballs were prominent; external muscles of eyes normal; papilla normal; corneal reflexes nornal; hearing normal in both ears. Left nasolabial fold not so prominent as the right; no defect of function in regions supplied by any other cranial nerve. Muscular power, sensation and reflexes of both upper and lower extremities were normal. There was some static ataxia; marked ataxic gait; patient staggering toward the right.

In the course of the following six weeks there were no new developments, exeep that the headnche and vomiting became worse, to the extent tirut they were very severe and almost constant. The gait became so ataxic that patient was not able to walk or stand without support. No choked disk developed. Diagnosis.-Cerebellar tumor, probably of the right side.

Operation.-A suboccipital decompression on the right side wns decided on, and the operation was performed by Dr. Horace Whitacre. No tumor was found. The cerebello-pontine angle was explored. 'The intracranial pressure was very great.
About one-third of the right lobe of the cerebellum was removed.

Result.-The inmediate result of the operntion was a com. plete relief from headache and vomiting. There was some ataxia of the right hand after the operation. After two weeks the patient was able to sit up, and gradually began to walk. His gait, however, was decidelly ataxic. During the four weeks at the hospital, following the operation, he suffered but one headache. Five months after the operation his condition is fair, but he does not walk much better and lins occasional attacks of headache.

Cass 6.-Patient.-M. M., a woman aged 36, was referred to me by Dr. F. Forchlieimer on June 14, 1909. Patient was ill when an infant, but has since been in good health. Had influenza and whooping-cough four years ago. Had infuenza nine weeks ago; since then constant headaches; partly frontal, partly occipital, the pain rndiating into the shoulders. Had vomiting spells almost daily since the headache beame con. stant. Had vertigo when the head was moved from side to side, or when asked to walk. Vision gradually failed, until patient was unable to read ordinary print.

Examination.--June 14, 1909, Facial expression one of great suflering; slight drooping of left eyclid; bilateral papill. edema discovered by $\mathrm{Dr}$. Walter Forchheimer one week ago; no loss of corneal reflexes; slight static ataxia when standing on right foot. The examination was otherwise negative.

During the next five weeks the condition gradually grew worse. Patient had repeated attacks of cerebellar spasms, during which there would be $n$ momentary loss of consciousness, with general muscular rigidity. She also lost the patellar reflexes in both sides, and occasionally had double vision. There was no loss of muscular power in the legs, but the ataxia beenme so marked that patient refused to walk, but was able to walk with assistance. The vision rapidly grew worse, and a suboccipital decompression was resolved on, the left side being chosen as the probuble seat of the tumor, on account of the drooping of the left eyelid and a tendency to stagger toward the left.

Opcration.-The operation was performed by Dr. Horace Whitucre. A cyst, about the size of an English walnut, was found at the seat of the operation. It was subcortical, involving the posterior portion of the cerebellum, and on opening it a pale amber-colored fluid was discharged, followed by a collapse of the lobe of the cerebellum. Recovery from shock and anesthesia was rapid.

Results.-Headuche and vomiting ceased for a while, and the vision improved greatly, but the other signs remained unchanged. The choked disk continued, the double vision likewise. The patellay reflexes did not return. A sinus established itself automatically, and cerebrospinal fluid escaped in large quantities. After two wecks the headache and somnolence returned. There was an ocensional attack of vomiting. There developed an acute ataxia of the left arm and leg, which rendered the patient unable to walk at all. There was also a marked weakness of the left arm. Incontinence of urine and feces developed, and there was a return of the cerebellar seizures. At this time I went away on my summer vacation and left the case in charge of 1)ry. Whitacre and Langdon. An attempt was made to relieve the patient by draining the lateral ventricles, but the patient died within twenty-four hours after the operation.

\section{TOIOGRAPIIC DIAGNOSIS OF CEREBELLAR TUMOHS}

The chief interest in the study of the differential topographic diagnosis of tumors below the tentorium cerebelli is whether we have arrived at that state of diagnostic acumen which will enable us to say with any degree of certainty whether a growth is located in the cerebellum itself, and above all, which lobe of the cerebellum is involved. I believe that we can say with some accuracy whether a growth is in the pons, or the region of the corpora quadrigemina, and I believe that the diagnosis of growths in the cerebro-pontine angle cinn be made with almost equal facility; but the great stumbling-block is offered by tumors of the cerebellum 
itself. We have seen what signs and symptoms are jeculiar to neoplasms of the pons, of the region of the corpora quadrigemina and of the cerebello-pontine angle.

In arriving at a diagnosis of tumors of the cerebellar hemisphere our first step is one of exclusion; we must cxclude tumors in the above locations. Then we must cxclude frontal lobe tumors. We cannot here go into the symptomatology of frontal lobe tumors, but suffice it to say that there are well known physiologic facts and clinical and surorical experiences which attest the fact that at times it is practically impossible to say whether the tumor is in the frontal Jobe or in the cerebellum.

The physiologic fact to which. I refer is that the loss or disturbance of function of one cerebellar hemisphere when removed in animal experiments, especially the ataxia, quickly disappears after the operation, but if the animal is then deprived of the opposite frontal lobe, all the cerebellar symptons return. In a word, the frontal lobe in a measure takes up, or at least compensates for the loss of the function of the crossed cerebellar hemisphere. 'This interaction of function takes place through the fronto-bridge-cerebellar tract. It is also a well-known. fact, that tumors of the frontal lobe, both by causing ataxia, and by producing distance pressure signs, can cause a symptom-complex, which at times can hardly be distinguished from a cerebellar symptom-complex. Moreover, it is not unusual to have unilateral spasms and even Jacksonian seizures in ecrebellar lesions, as the cases of Mills and Weisenberg and Case 4 of this paper show, which complicates the matter still more.

\section{FRONTAL 'TUMORS}

Following is a short history of a case of left frontal ilimor:

('Ase 7.-Patient.-G. von I., aged 41 , was admitted to (in. rinnati Hospital Aug. 5, 1901, in a maniacal state, complaining of pain in the left occipital region. He denied venereal diseases and alcoholism. The patient was unuble to give a history of his case. According to the wife's statement, he had fuiled in business six months previously; nuch worried. lior the past six months she noticed a mental deterioration; he did not scem bright; was forgetful. For previous two months he had complained much of pain in the left occipital region. Six weeks before admission, while beating a carpet, patient suddenly staggered backward, was supported to a chair, stared it his wife, was unable to spenk, became blue in the face, but did not lise consciousness. At the same time he had a spasm in the right leg, but none in the right arm. The patient said that he felt as if he were going up to the ceiling. He had about ten such attueks that night, three or four the next day and then they became less frequent and finally stopped. This wis followed by formication and numbness of right foot. later he had an attack of paralysis of the right side, which soon passed away and pationt returned to his business. There was no lnendache or vertigo during this period. At times the patient would stagger and show a tendency to fall to the right side, and could not walk without support for the past few dnys. After a severe attack of pain in the left occipital region a few days before admission, patient had numbness and weakness of the right leg. He began to vomit and had attacks of vertigo. At night he became delirious and in a few days became maniacal and was brought to the hospital.

Examination.-Mental condition was bad; could be aroused from stupor, but was unable to give an account of himself; did not seem to understand the questions put to him; did not speak voluntarily; when asked a question, repeated it slowly, but gave no nnswer. Paresis of left facial was present; paresis of left side of tongue doubtful; patient was unable to state whether right hand was wenk or not on account of mental condition; right leg was dragged when patient attempted to walk. Patient fell to right side. There was no ankle-clonus; no Babinski in riglit side. On ophthalnoscopic examination double choked disk was observed, with hemorrhagic retinitis; right pupil larger than the left; left pupil did not respond to light; right one responded. Slight ptosis of right eyelid; paresis of external rectus of both eyes.

Operation.-An unsuccessful operation was done over left cerebellar hemisphere. Patient died within thirty-six hours.

Autopsy.-Autopsy revenled a tumor the size of a len's egg, which grew from the durn on the lower surface of the frontal lobe up into the frontal lobe. It was not infiltrating, and the frontal lobe surrounded the tumor like a shell.

This patient was operated on for a cerebellar growth chiefly owing to the fact that there was a hemiplegia alternans, involvement of the external reeti of both sicles and history of a staggering gait with tendency to fall to one side.

Only recently an autopsy was made in a similar case in which one feature of the clinical history was that the patient at times had a staggering gait. Dercum recently reported a similar case, in which the operation was made over the cerebellum and the autopsy revealed frontal tumor. We are gradually, however, improving our knowledge of frontal growths, as well as of those of the cerebellum. I believe that we shall make fewer mistakes along these lines if we pay greater attention to the chronologic orter of the development of signs and symptoms, and I believe that in frontal growths some change in the mental state will occur, and will often even antedate the general symptoms of brain tumor, wherens, mental symptoms if they occur at all, occur late in cerebellar tumors. In at least two cases of frontal tumors in my observation the mental deterioration was manifest, the above history showing that the patient at times even became maniacal, and was brought into the hospital in this condition. In the other sase, which I reler to above, aside from a progressive loss of vision and the ataxia, there were no mental symptoms, cxcept a remarkable euphoria, a cheerfulness which continued to death, lasting over four years, which is certainly unusual in brain tunior cases of other location.

Only recently lieich has slown that we may even have areflexia cornca, which is looked on as a positive diagnostic sign of tumors of the cerebello-pontine angle, in frontal tumors. 'This, however, is so rare that it need not complicate the diagnosis.

\section{ISEUDOTUMORS OF TIIE BRAIN}

In making the diagnosis of cerebellar growths, we must also rule ont pseudotunors of the brain, a subject which has been placed on record by Nonne, Oppenheim, myself and others: 'This pseudotumor symptom-complex is more apt to resemble the cerebellar symptom-complex than any other. Its pathology is unknown. 'The autopsy in one of my cases was entirely negative, so far as the brain was concerned. IIere is a summary of the typical syndrome: hoadache, violent vertigo, vomiting, bilateral choled disk, paresis of the external recti muscles of the eyes, areflexia cornea, especially of the right eye; timnitus, with diminished hearing on the same side, cerebellar atuxia and deflection of head and even entire body to one sicke. These signs of pseudotumor are in a manner similar to acquired internal hydrocephalus or serous meningitis. These two conditions nust be ruled out, and the only means at our command are the presence of other signis and symptoms, on which I shall presently lay stress, which are present in cerebellar cases, and absent in the abore symptoncomplexes. 


\section{PITYSIOLOGY OF THE CERERELIUTI}

A few words on the physiology of the cerebellum will be in place here. The chief function of the cerelsellum as ascertained by animal experimentation, is that of automatic coordination. Through the medium of the cerchellar tract, Gowers' tract, the posterior column cerebellar tract, aud the vestibular nerve, all of which Bruce holds end in the cortex of the vermiform lobe, the rerebellum obtains knowledge of the state of contraction, and the tone of all muscles of the body and the position of the body. When these tracts are interfered with within the cerebellum we have the chief symptom of cerebellar disease, viz., cerebellar ataxia. Lesions of the cerebellum, however, are not the only factor in the production of cerebellar ataxia. We know that tracts lead from the cerebellum to the pons through the corpora yuadrigemina and to the opposite cerebral hemisphere, and that the destruction of any one of these tracts will cause cerebellar ataxia. Hence, lesions of the frontal lobe, of the corpora quadrigemina and of the pons may ranse cerebellar ataxia. In the lesions of the cerebellum, however, we have ataxia without any associated signs, such as will form part of the syndrome in lesions of the frontal lobe of the corpora quadrigemina and of the pons. In considering cerebellar ataxia and other signs of cercbellar lesions we must not forget, that the loss of function of one cercbellar hemisphere, as Munk and others have shown, may be compensated by the opposite frontal lobe, and that symptoms may disappear; or that disease of one hemisphere may even run a latent course. Balbinski lays much stress on a physiologic phenomenon which Munk attributes to the cerebellum, viz., a harmonious interaction between the movements of the extremities and those of the trunk. Babinski calls this function synergie and the loss of it asynergie crebclleuse. By this is meant a loss of harmony, which shows itself when walking, for instance, by an attempt to bring the leg forward, while the trunk does not change its position or may even go backward. 'This symptom was typically illustrated by the tendency to retropulsion on attempting to walk in Case 1 , or by the inabjlity in Case 2, of the patient to walk forward when the eyes were closed. Asynergic cerebellcuse may be confined to one side-hemiasynergy-as in Case 6 ; and Babinsli says that it points to a lesion of the cerebellar hemispluere on that side or to one of the tracts leading to the hemisphere, or from the hemisphere on that side. Oppenheim seems to agree to this; Spiller dissents. Foreed movements are seen in animals, rolling movements, but Munk does not attribute them to lesions of the cerebellum, but to other causes. In the human being we see a tendency to assume certain positions in bed, or to hold the head to one side, the diagnostic value of which we will consider later.

Astasia-alsasia, hemiataxic movements, homolateral weakness of muscles, homolateral convulsions, will be consiclered as localizing sigus later on, as will also speech disturlounces and nystagmus, all of which have been attributed to loss of function of the cerebellum.

\section{TOCAL SIGNS}

What are the focal signs which clinical experience has taught us as pointing to tumors of the cercbellum? 'The following syndrome calls for analysis:

1. Cerebellar ataxia.

2. Atactic movements, hemiataxia, asynergie cerebelleuse, Jirmiasynergy and tremor.

3. Vertigo.
4. Nystugmic jerking and other cye-muscle signs.

5. Atonic paresis of trunk and extremity muscles on one sidk.

i. Adiadokokinesia nnd speech disturbances.

7. Convulsions, unilateral or bilateral.

8. Attitude of the head.

Let us take up the signs and symptoms in the order as they are griven:

Cerebellar Ataxia.-The typical, reeling staggering gait is probably seen only in tumor's of the vermiform lobe. Perhaps also in quadrigemina tumors (Case 1), but here it will be associated with extensive eye-palsies, which will be absent in the cerebellar lesion.

What is more commonly scen is staggering to one side and a tendency to fall to one side. I believe that when unassociated with pontine signs or symptoms, this may be looked on as fairly characteristic of lesions of the cerebellar hemisphere. It would be of great value, if it could be established as a law, that the patient reels or falls to the side of the lesion. Weiscuburg secms to think that this is the case. Two of my patients showed a temlency to fall toward the side of the lesion; one did not. Oppenheim and Siemerling and Spiller hold that we cannot rely on this sign as pointing to the side of the lesion. Siemerling says that cerebellar ataxia may be entirely absent. . If the vermis is the seat of the growth, the ataxia may be so great that the patient is unable to stand at all. This is true likewise of growths of the corpora quadrigemina, as Case 1 shows; but in advanced cases, as Nos. 3, 5 and 6 show, may be present in pressure in or on the lateral lobes, or in tumors of the brain stem. But this may be explained by distal or contiguous pressure on the vermiform lobe or cerebellar tracts, in all three of these cases.

Hemiataxia and Memiasynergy.-These, which Oppenheim thinks may be iclentical manifestations of cerebellar incondination, are often present, and may, after further investigation, be found to be of great topographic diagnostic importance as pointing to lesions in the same sicle of the cerebellum.

Bruns says that hemiataxia is a valuable sign, because it occurs carly, and is a sign of an intracercbellar lesion. In the four cases reported by him it occurred in the homolateral arm in each case.

Soques reports hemiasynergy and adiadokokinesia on the same side, homolateral, in a case of tumor of the cerebello-pontine angle.

In Case 3 , presumably a pons tumor, very marked hemiataxia, perhaps hemiasynergy, and certainly adiadokokinesia, developel four or fire months after the onset of the first symptoms.

The homolateral ataxia which was seen in Case 5 after the operation, is in effect a physiologic observation. No tumor having been found, a large portion of the cerebellar hemisphere was removed, and the homolateral ataxia was noticed after a few days.

In Case 6 there was static ataxia of the right log (side of cyst), before the operation, loss of jatellar reflexes and atony of both legs, but no loss of muscular power. The ataxia became so marked that patient refused to attempt to walk. After the operation the ataxia of the left arm and leg became very acute. In a word, the cyst was found on the left side, and the ataxia was most marked on the left side, the right arm and leg being free. When ataxia is suspected but not present in the ordinary way of standing or walking, Oppenheim recommends that the patient be placed in the ordinary Romberg position, and be asked to bend forward with closed eyes. As a rule, not only will the 
Joss of equilibrium show itself, but also the side toward which the patient sways, will show itself. Some stress lats been laid on unilateral tremor of multiple sclerosis, as a sign of cerebellar disease. Collins, Bruns, Siemerling and Oppenheim have called attention to this sign, and when present, it is usually lomolateral.

Atonic Paresis.-Atomy of the trunk museles on siele of the lesion, homolateral weakness in the atartic limb and loss of patellar reflexes on one side or both, may oeeur, as seen in Case 6 . Bruns says that it oceurs only in acute cases after removal of a part of the corebellum. Siemerling says that it is still a debatable sign. $A$ sudken and acute onset of astasia-abasia, clisappearing just as suddenly, was sem in Case 3.

Vertigo.-This, which is invariably present in sul)tentorial growths, is not of much localizing value. The exact differentiation between vertigo of intra- and extracerebellar origin, as definch by Stewart and Holmes, has not been verified by otliers and needs further investigation, namely, that in intracercbellar tumors the objects and the apparent movenients of their own bodies are from the side of the lesion to the opposite side, and in extracerebellar tumors the apparent movement is toward the side of the lesion. If, however, vertigo is brought about hy changing the position of the body or of the head, we may safely say that this oceurs when the body or the heid is turned away from the side of the lesion.

Nystagmus.- Not the typical nystagmus seen in multiple selerosis, but a nystagmie jerking, when the eyes are turned to one side or the other, is frequently seen in subtentorial growths. Munk says that strabismus and nystagmus are not secn in animals as a result of the removal of one-half of the cerebellum, but as a result of injuries to the neighboring parts. Sicmerling, although admitting it as a sign of intracerebellar lesion, thinks that it is caused by pressure on the pons or corpora quadrigemina. H. Neunan and Collins look on it as a cerebellar sign. Nystagmic jerking is usually seen when the eyes are turned toward the sicle of the lesion, but this is not the invariable rule. It was present toward the side of lesion in Case 3 . It was not present in Case 5 either before or after the operation; nor was it present in Case 6.

Spiller, in a case of cerebellar abscess, says that the nystagmus beeame more marked. when the patient looked toward the seat of the lesion. H. Neuman has conformed this in a later communication.

Siemerling does not fecl that the direction of the nystagmus has a positive localizing value, while Oppenheim thinks that nystagmus may be a sign of intracerebellar disease, although it more frequently is the result of distal pressure. I have never seen general ataxia of the cyeballs such. as Spiller and Weisenburg describe in a subtentorial tumor, but have seen it in a case of nuclear degeneration of the center's in a case of chronic bulbar palsy.

Attitude.-In this respect, I wish to call attention to the fact that the position of the head and the position of the body have a marked influence on bringing out signs of cerebellar tumors that may be latent. In Case 3 nystagmus occurred only when the eyes werc turned towurd the seat of the lesion. Oppenheim in a recent article gives his experiences on this subject. $\mathrm{He}$ cites two cases of tumor of the cerebellum in which a nystagmus was only slightly indicated when the patients, in a standing position, looked to one side or the other, but which become very marked even when the eyes were at rest, if the patients reclined on one side. In another (ase in which nystagmus was absent when standing or lying on the back, if the patient lay on his right side and looked toward the left, nystagmus appeared at once, and a paresis of the external rectus became apparent. In another case, nystagmus on looking toward the side of the lesion appeared only after the patient had been turned on a revolving chair, two or three times. In two other cases of subtentorial tumor's, areflexia cornea was produced by having the patient lic on the side opposite to the tumor.

Convulsions.-General convulsions or unilateral conrulsions, of the cerebellar type, viz., opisthotonos, momentary loss of consciousness with a general clonic spasm of very short duration, are indicative of subtentorial pressure and irritation of the pons, rather than of intracerebellar tumor. They were seen in Case 6 (cyst of hemisphere), as well as in Case 3 (tumor of cerebello-pontine angle). Probably one of the most valuable signs which will indicate the side of the lesion is one to which Babinski has called attention, namely:

Adiadoliohinesia.-By this is mont a slowing of movements of an alternating claracter, and is best illustrated by successive pronation and supination of hand and forcarm. In lesions of the cerebcllar hemispheres there is a markel dimimution in the rapidity with which these movements can be alternated, and oecurs always on the homolateral side. Oppenheim and Collins and Siemerling lay much stress on this sign, and especially Siemerling, who says that he always found it after his attention was called to it.

Arliadokokinesia, according to Boenhoefter, who describes speech disturluance in a cuse of cercbellar tumor, manifests itself as bradyphasia; he says that it is due to an inability of the patient to rearrange his lip and tongue muscles rapidly, which is necessary for fluent speech. Other speech disturbances have been ascribed to cerebellar lesions, as a staceato, jerky mode of talking, which has been attributed to incoordination or ataxia of the muscles of tongue, lip and larynx. Speech becomes slow, repetition of long words causes a choppedoff reproduction, and at times stumbling and stammering. Rapid speech is impossible, but there is no anarthria. The attitude of the head may give us some indication as to the side of the lesion. Baten called attention to the fact that the head is inclined in such a way that the occiput points to the side of the tumor, and the chin is pointed away from that side. Collins, in a case of hemorrhage, describes just the opposite condition. Oppenheim says that there is no rule, but that the patient assumes such a position of the head and bolly as cause him least inconvenience. Spiller also thinks that there is no rule. In my cases I could not confirm the rule. Sholz has used the Neisser puncture test to determine the side of lesion, and located the tumor in two out of three cases by this means. Oppenheim calls attention to a difference in the percussion note on the two sides, and says that we may find more dulness on the side of the lesion. Bruns calls attention, especially in children, to tenderness on percussion, and the cracked-pot sign, on the side of the lesion.

10 West Seventh Strect.

B!BLIOGRAIHYY

Releh : Berl. klin. Wehnschr., 1008, No. 9. p. 476

Nonne: Deutseh. Ztschr. f. Nervenh., xxv, isn.

Oppenhelm : Lehrbuch der Nervenkrinkheiten, 1908.

Oppenhelm: Lehrbuch der Nervenkrankheiten, 1908.
IIoppe: Jour. Nerv. and Ment. Dis., February, 1007.

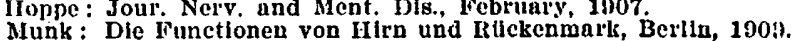

Babinskl : Rev. Neurol., 1899. 
Weisenburg: Dingnosis of Tumors and Other Lesions in the Cerebello-l'ontile Angle, 'THe Jutuxas A. A. A., April 18, 1908, b. 1251 .

Oppenbelm : Neurol, Centralbl, 1010, Nos. 3 and 7.

Bruns: Gehlrugeschwillste.

Slemerling : Berl. klin. Wehnschr., 1008, Nos, 13 and 14.

Collins: Med. Itec,, Ixxilt, $\pi 63$.

Bubinsk1: Kev. Neurol., 1902 , No. 21.

Neuman: Arch. $\mathrm{f}$. Ohrenh., Ixvil, 191.

splller: in l'osey and Spliler's 'The liye and the Nervous System.

I3oenhoefter : Mountschr. P, l'sychint. xxiv, 379 .

Boenhoeffer : Mountschr. P, P'sychint., $x \times 1$
Bruns : Neurol. Centralbl., 1004, p. 578 .

Sociues: Laris Neurolog. Soc. lteport, 1000.

\section{ABST'RACT OF DISCUSSION}

ON PAPERS OF DRS. HOPIE, LANGDON AND KMAMER, AND GRINKEL

Dh. C. H. Huanes, St. Louis: Papers of this character are a]ways exceedingly interesting from the light thry give us on the subject of diagnosis. Symptomatically in all we have choked disk and titubating, unstable gait. No paper has yet been given presenting a case so markedly unilateral as to give us that characteristic symptom in the gait, of a disposition to describe a semicircle in the walking of the patient.

The subject of brain tumors becomes especially interesting for the purpose of diagnosis, particularly focal diagnosis, as they impinge on the origin or a course of certain cranial nerves. 'Tumors of the posterior portion of the brain and cerebellum often result in loss of vision which is quite characteristic, but the tumor in the white matter of the brain causes choked disk only from the general involvement of the brain, and its congestive condition apparently, so far as my observation has gone.

When as a surgeon, I was called to preside over a hos. pital for the insune, I used to think that it was the province of a surgeon to operate in every case when opportunity off(red, especially for epilepsy and tumors. 13ut 1 am not so hasty now in operative suggestion. I recall an instance of unilateral involvement of the cerebellum accompanied by the characteristic tendency to describe a circle on the opposite side of the lesion in attempting to walk; I was agreeably surprised in that case, after the use of extensive doses of catliarties and sodium bromid, etc., to see that symptom disappear. Notwithstanding, the man died and I made the autopsy which MeLean Hamilton reproduced in his classical work on that subject at the time. We have not all the liglit that is coming to us yet on the subject of tumors, but we are getting more light than we liad some years' ngo.'

DR. G. W. HAL,, Chicago: In one case that J). Grinker reports, the patient, who eame on my service at the Cook County Hospital, showed the typical findings of the. process in the right cerebello-pontile angle, and the question at that time so far as the dingnosis was concerned was whether or not there was an alscess or tumor. As Dr. Grinker brought out in the history of the case, it was at first very puzaling, because the patient had also a discharcing ear; but the fact that the ear had been punctured by a plysician, on the outside, at a more recent date than the onset of the symptoms, onsily cleared up the history, sufliciently to guarantee the advisability of an operation.

In connection with that case I might mention also the conditions which Dr. Hoppe brought out as to frontal tumors. No one can make an absolutely accurate diagnosis as to localization of tumors of the brain perhaps outside of the cerebellopontile angle. We have' seen instances occur in which rliagnosis of cerebellar processes have been made, and the processes were found in the frontal lobe or in the brain proper.

1)r. Hoppe's statement as to the mental symptoms occurring in the frontal tumors rather than in the cerebellar tumors secms to be a point well taken. 'Jhat was especially dwelt on by 1)r. Beevor in one case he load on his service in the hospital at Queen's Square, London, in which he made the probable diugnosis of a frontal tumor rather thun a tumor of the cerebellar proeess beculuse of certain mental symptoms present in that case.

Dr. Charles L. Dana, New York: A few years ago the subject of brain tunors had become interesting, because the suceess of surgical intervontion was so poor, but in the last four years we have been much more successful in localizing and removing tumors, especially subtentorial tumors. In listorical justice to American neurologists, Dr. Grinker ought to state that the at tention to the clinical facts regarding tumors of the cerebellopontile angle, was first brought out by Dr. IIunt and Dr. Franckel about four years ago in a series of papers and report which they made at that time; it antedated any emphatic recognition of these tumors by any forcign or American ueu rologist or surgenn that I know of. At that time they reported several cases and three operations, all unsuccessful; but they then drew attention to the fact of the ease with which such tumors can as a rule, be recognized. One point which they made was that in some of these patients there was a neurofibromatosis of the skin, so that in some enses the possibility of $n$ tumor of the cerebello-pontile angle was suggested by the fact that a great many little fibromas of the skin lad been noticed in the patient.

There is a symptom in cerebellar disease sometimes seen in tumors, hemorrhages and softening and atrophic conditions, that is, a certain tendency to catatonia.

The cerebellar seizures that have been referred to vary somewhat in character, but are most frequently, I think, eitler sudden plunges forward or sudden droppings down by the patient as though he liad been struck by lightning, or suddenly fainted; at other times the patients fall down and assume the sprawling attitude and tonic spasms such as are seen in animals experimentally operated on. These cerebellar seizures generally come from lesions that begin from an extramedullary source--tumors of the pontile augle or of meningeal origin.

Dr. Tinnonore Diller, Pittsburg: Those who attended the Setion last year at Atlantic City will remember a patient that I showed before the Section at that time, from whom a cerebellar tumor had been removed. This patient suffered from very severe headaches, showed a high grade of optic neuritis, 6 or $7 \mathrm{D}$., and had a posture of the head to the left, away from the tumor. 'The tumor was removed from the anterior margin of the cerebellum after about one-third of the cerebellar lobe had been removed. I saw this patient about a month ngo; lee is working on a farm. His gait, which was extremely uncertain, is good. IIe is entirely free from pain. He says that lee sees well, and is comfortable in every way, and the only thing that we can discover wrong with him is a moderate grade of optic atrophy. 'This case is now of about eighteen montlus' standing.

I commend very much J). Jfoppe's method of presenting his case here todny by the pictures. It is difficult to transport specimens to a meeting; but stereopticon views like these give as plain a perspective view of the tumor as the actual specimen would.

With regard to this point of the confusion between frontal and cerebellar lesions, let me say that recently I saw a patient whose history was that he had fallen, and that an operation had been done in the frontal region, and a small amount of pus removed a year ago. When $I$ saw this patient he was having a great deal of pain in the occipital region; he was complaining of very severe pain confined to the frontal region and his hend was extended backward very far. He liad no fever; and he had not the slightest pain in the frontal region. We hurried him off to the hospital. An operation was done over the frontal region and an abscess was found immediately below the site of the old wound, and I think fully an oulice of pus came out. The case is very striking. The only thing the man complained of was very severe pain in the oceipital region (not localized as to the side-probably bilateral), and this was due to an abscess in the frontal lobe.

Dr. D'Orsay Inchit, Chicago: The interest taken in cerebellar neoplasms and the discussions arising therefrom, have resulted in a gratifying percentuge of accurate localizations in operations in this region. 'This' is particularly true of cases with acusticus symptoms. As soon as a suspected tumor pre. sents in a marked degree eighth nerve involvement, the tendency is to designate it as a cerelvello-pontile angle tumor. I should like to get some expression from the members with regard to the propricty of calling tumors, necessarily wide-spread in their extent over the cerebellum or in the cerebello-pontile space, angle tumors. We are in truth not dealing with an angle, so far as the invasion by tumor of this area is concerned. We are 
rather denling with a quadrilateral spaces. something that lus more of the configuration of a rectangle. I feel, therefore, that if we gret away from the designation of angles in these cases wo muy be serving eranial topography with more accuracy, so $f_{\text {ait }}$ "s this site of predilection for certain tumors is concerned.

In 1)r. Grinker's puper. I think that, aside from the complete ruport of his cuses, chief interest centers in the character of his summary, in which he dwells upon the question of gliona and sarcoma, as well as the expediency of lumbar puncture. I think that we as neurologists are quite agreed that lumbar puncture of itself is a relatively innocuous adjunct to our diagnostic techuic, but it may prove a decidedly dangerous measure in the presence of a brain tumor. Perhaps this particular fact is not sufticiently impressed on internists or general practitioners. 1 have not infrequently heard physicians who busy themselves more or less with the modern routine in neurologic exnmination, ask whether a lumbar puncture has been made, forgetting. 1 think, that lumbar puncture may be of real danger to the patient when we are dealing with obvious symptoms of intraclunial pressure of tumor origin. I should advise extreme conservatism in doing lumbar puncture in this type of case.

1 think, too, that in those cases in which cerebral tumor of wolid formation is suspected, we are not infrequently surprised to find a cyst, capable of evacuation, and therefore yielding a better prognosis than was admissible from the premises prior to operation. I reenll such an experience five or six months ago, when it was ny privilege to see a case of brain tumor at the request of Dr. Alfred Murray. I made a localization of cerebellar tumor and the patient was operated on by Dr. Albert di. Halstend, of Chicago. The acusticus findings were of very material value in referring the tumor to the cerebello-pontile space (or angle, if you wish) and on a very extensive decompression, exposing both sides of the cerebellum very widely and spaciously, it was found that the stuspected area was filled with a fairly large cyst, which was properly evacuated, and at a recent date, the patient was doing very well in his own home, and able to be up and about, for a tine even following his oceupation as " ploarmacist.

I ngree with Dr. Dann that we should not forsake the old and well-tried clinien] eriteria in arriving at a localization, but, on the other hand, I feel that we should put due emphasis on some of the newer additions to our technic and credit with importance such a symptom as, for instance, has been advanced by the French sehool, and called "adiadokokinesia," I have noted it in several instances, and I think, as an evidence of asynergy, it is quite as importunt as are other symptoms entering into the question of the coordinating function, as it depends upon the cerebellum.

Dr. Jundus Gmokr, Chicago: I wish to emphasize a point of general practical interest, numely, that hysteria and neurasthenia are dingnosed often in cases requiring more extended investigation. I recall several such cases of my own, in which the symptoms at flrst pointed to functional disense, but brain symptoms developed later and the diagnosis of organic discase lind to be made.

One point which has not received due emphasis in this discussion is that cerebello-pontile angle tumor may begin with licmiplegie symptoms. My third ease, which for lack of time could not be reported in full, was diagnosed as hemiplegia at a time when there were hemiplegic manifestations in the form of one-sided asthenia, that is, a unilateral weakness resulting from cerebellar atonia. In these cases there is neither exaggeration of reflexes, nor Babinski sign.

I am very thankful to Dr. Dana for correcting my short reference to the historical development of this subject. It is quite true thint Drs. Hunt and Franckel were the first to call attention to tumors in the cerebello-pontile angle; they also furnished splendid contributions to the symptomatology.

In my opinion the new cerebellar sign described by Babinski under the term "adiadokokinesia" is not valueless. When present, it is a reliable sign. It is more often absent than present and frequently it only appears after an operation has been performed on the cerebellum, certainly too late to be of value in diagnosis. In one of my cases this symptom was present before any of the other's. While, then, this sign may not be of the greatest value, we may nevertheless consider it, if only the observation may scrve to determine its proper place in the symptomatology of cerebellar tumor.

Staggering to one side is not a reliable focul sign. In two of my eases the stuggering was on the side of the tumor; in the third case the patient staggered to either side.

Concerning speech disturbance, my first case showed an ut teranee which might be called "jerky" speech, rather than bradyphasia. The so-ealled "cracked-pot" resonance I have not found in my chses, but I have often observed it in the hydrocephalus of children.

\section{EHRLICH'S BIOCHEMICAL THEORY, ITS CONCEP'TION AND APPLICATION*}

\section{LOUIS HART MARKS, M.D.}

Follow of the Royal Institute for Experimental Therapeuties

\author{
PRANKFOR'T A. M., GERMANY
}

It is my privilege in this paper to take up the subject of specific chemical therapentics. which is equivalent to saying that I am to expound the work that Professor Paul Ehrlich has accomplished in the past seven years, during which time he has done far more than merely lay the foundation of this new science. It can be said that this basic idea, which he has followed logically from the rery beginning of his experimental work, down through his present world-stirring discovery; namely, that a specific chemical affinity exists between specific living cells and specific chemical substances, is his main, most valuable, broadest and most suggestive contribution to science.

It was this jdea that was at the foundation of his famous studies on the morphology of the cellular constitution of the blood. As is known, filmbich was the first to describe correctly the leukocrtes, and to teach us to differentiate not only different parts of the body of the leukocyte from one another, but also the different linds of leukorytes one from the other, by showing that these different parts stain differently with the same dyestuftis.

Following up this work in the field of morphology lie studied vital staining and demonstrated even more clenrly the selective action of many different substances for different tissues of the body. The best-known experiment in this comnection is the one performed with methylene blue, whereby he showed that if the substance be injected directly into the circulation, on section of the animal some time later, the tissues of the nervous system will be the only ones colored blue. He found further that those cells of the body which demand the most oxygen would not be colored at all, but would turn blue aficin an exposure to the air. This led to the publication of a work which stands out as a beacon light in the renlm of science, and is surpassed only by his original publication of his fundamental theory concerning the distribution and selective action of chemicals in the human body.

Further following out his idea he happened to feed mice with ricin and abrin, the vegetable poisons contained in the castor oil and jequirity beans, and found that he could immunize them against these poisons. Not only was this the first time that animals were highly immunized to vegetable poisons, but it was also the first time that the degree of immunity was definitely known. He also discovered the coagulative action of ricin on the red blood-corpuscles and found

* Delivered by invitation before the Anglo-American Medicul Assoclution of Rerlin, Sept. 10, 1910.

1. The Oxygen Requirements of the Organism. 